This item was submitted to Loughborough's Research Repository by the author.

Items in Figshare are protected by copyright, with all rights reserved, unless otherwise indicated.

\title{
Optimised performance of the backward longswing on rings
}

PLEASE CITE THE PUBLISHED VERSION

PUBLISHER

(C) Elsevier

VERSION

AM (Accepted Manuscript)

LICENCE

CC BY-NC-ND 4.0

REPOSITORY RECORD

Yeadon, Maurice R., and Mark A. Brewin. 2019. "Optimised Performance of the Backward Longswing on Rings”. figshare. https://hdl.handle.net/2134/6415. 
This item was submitted to Loughborough's Institutional Repository (https://dspace.lboro.ac.uk/) by the author and is made available under the following Creative Commons Licence conditions.

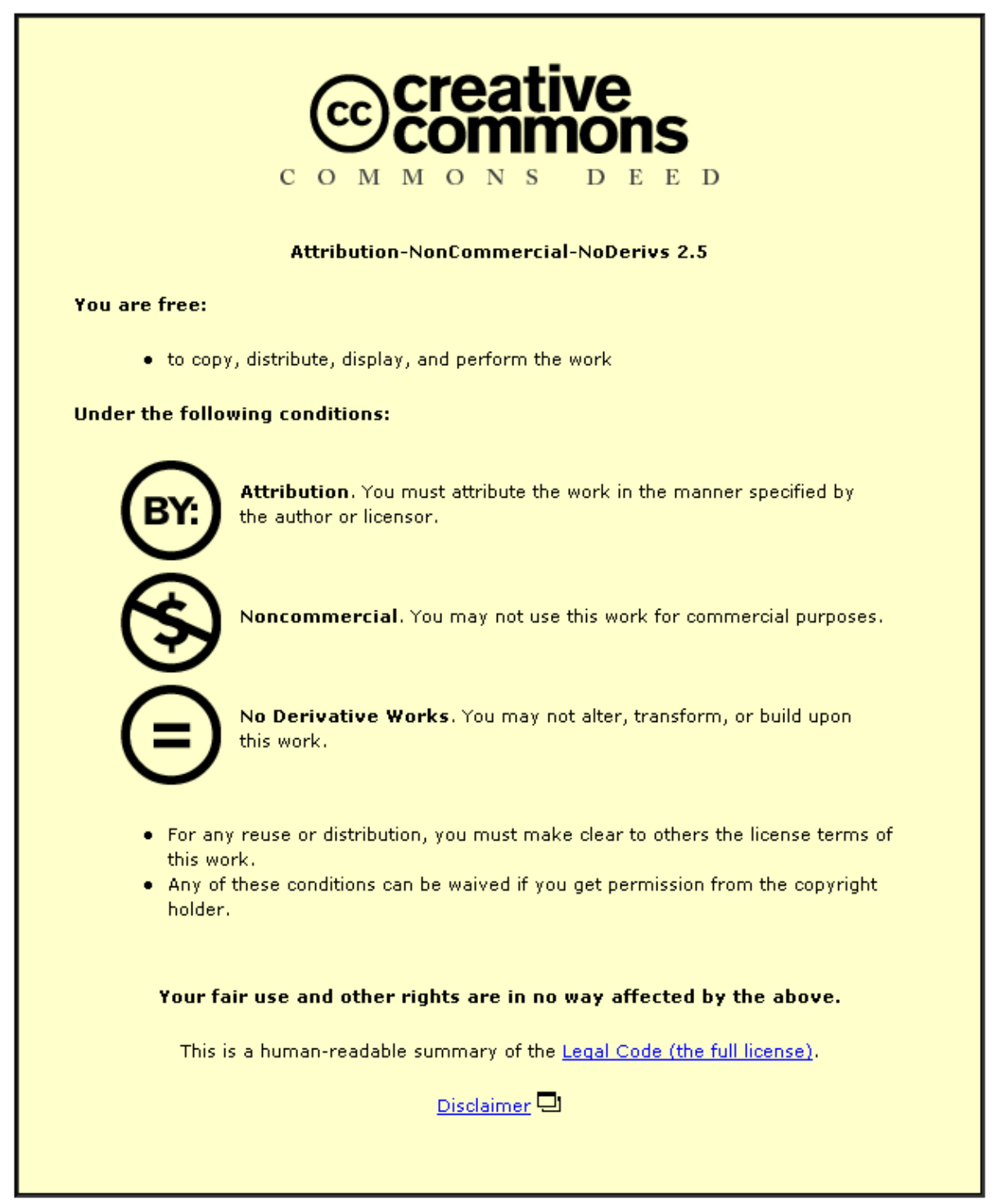

For the full text of this licence, please go to: http://creativecommons.org/licenses/by-nc-nd/2.5/ 


\title{
Optimised performance of the backward longswing on rings
}

\author{
Maurice R. Yeadon ${ }^{1}$ and Mark A. Brewin ${ }^{2}$ \\ ${ }^{1}$ School of Sport and Exercise Sciences, Loughborough University, Loughborough, LE11 3TU, UK \\ ${ }^{2}$ Department of Sport and Exercise Science, University of Bath, Bath, BA2 7AY, UK
}

\begin{abstract}
Many elite gymnasts perform the straight arm backward longswing on rings in competition. Since points are deducted if gymnasts possess motion on completion of the movement, the ability to successfully perform the longswing to a stationary final handstand is of great importance. Sprigings et al. (1998) found that for a longswing initiated from a still handstand the optimum performance of an inelastic planar simulation model resulted in a residual swing of more than $3^{\circ}$ in the final handstand.

For the present study, a three-dimensional simulation model of a gymnast swinging on rings, incorporating lateral arm movements used by gymnasts and mandatory apparatus elasticity, was used to investigate the possibility of performing a backward longswing initiated and completed in handstands with minimal swing. Root mean square differences between the actual and simulated performances for the orientations of the gymnast and rings cables, the combined cable tension and the extension of the gymnast were $3.2^{\circ}, 1.0^{\circ}, 270 \mathrm{~N}$ and $0.05 \mathrm{~m}$ respectively.

The optimised simulated performance initiated from a handstand with $2.1^{\circ}$ of swing and using realistic changes to the gymnast's technique resulted in $0.6^{\circ}$ of residual swing in the final handstand. The sensitivity of the backward longswing to perturbations in the technique used for the optimised performance was determined. For a final handstand with minimal residual swing $\left(2^{\circ}\right)$ the changes in body configuration must be timed to within 15 $\mathrm{ms}$ while a delay of $30 \mathrm{~ms}$ will result in considerable residual swing $\left(7^{\circ}\right)$.
\end{abstract}

Keywords: gymnastics, rings, longswing, simulation model, optimisation, performance sensitivity

\section{Introduction}

Judging criteria for the rings event in Men's Artistic Gymnastics stipulate that elite gymnasts must perform backward and forward swinging elements completed in stationary handstand positions to score highly in competition (F.I.G., 1997). The straight arm backward longswing (Fig. 1) fulfils these requirements and consequently is performed by many elite gymnasts. However, if a gymnast possesses appreciable motion in the final handstand, points are deducted, and a lower score is given for the routine. The ability to perform a backward longswing to a stationary handstand is therefore of great importance to elite gymnasts.

Previous studies of longswings have used two-dimensional analyses to identify differences in cable tension patterns between elite and non-elite gymnasts (Nissinen, 1983), to calculate net forces at the shoulders (Brüggemann, 1987) and to estimate resultant hip and shoulder torques (Sprigings et al., 2000). From observations (Fig. 1), however, it is clear that elite gymnasts make use of extensive lateral arm movements during the descending (b-d) and ascending (f-h) phases of the longswing, indicating that three-dimensional analysis of the activity is necessary. As a consequence, the previous two-dimensional studies may provide only limited insight into the performance of a backward longswing to still handstand. 


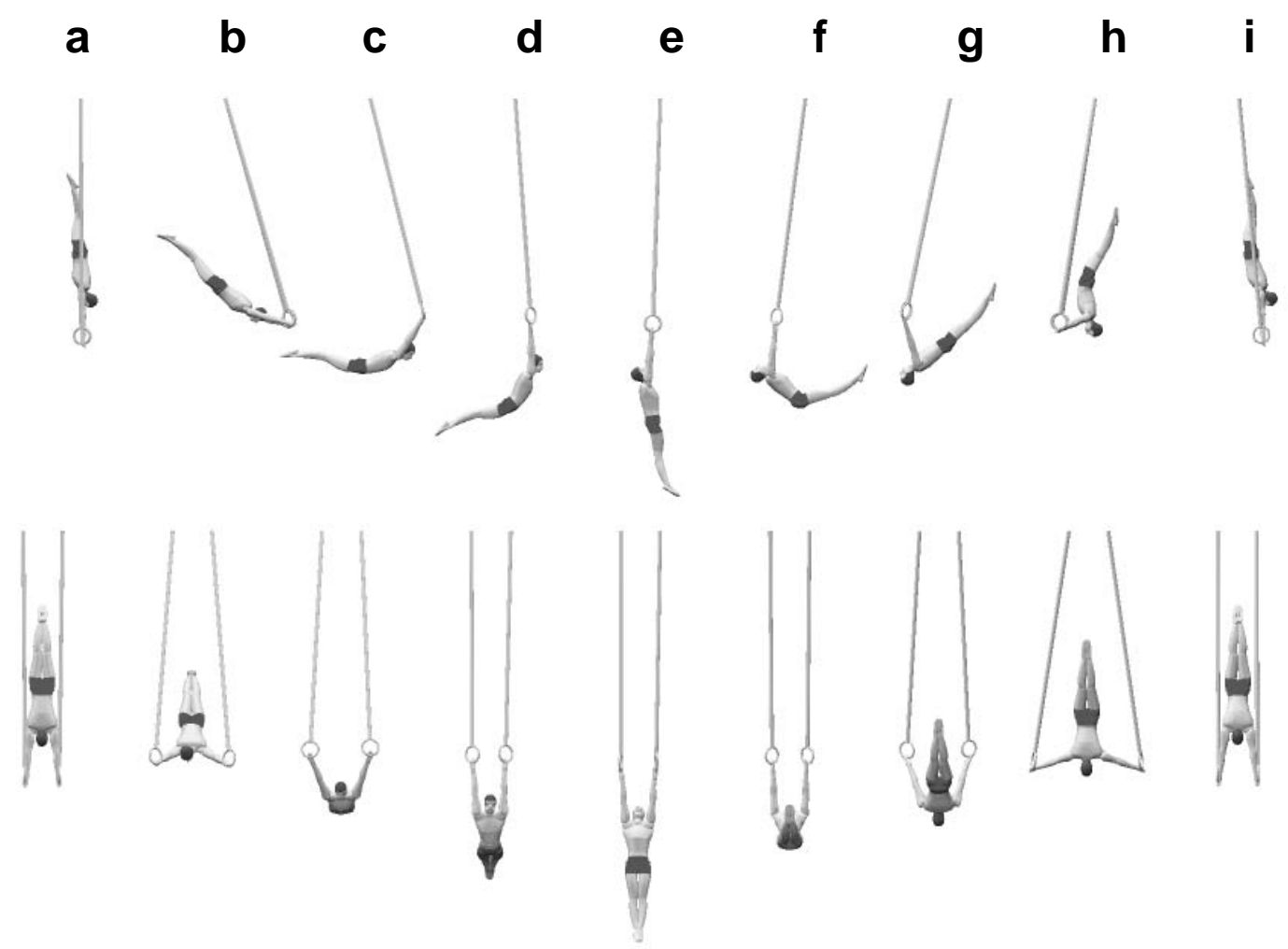

Fig. 1. Graphics sequence of an elite gymnast performing a backward longswing on rings from sideways (upper) and frontal (lower) views. Attention should be paid to the extensive use of lateral arm movements during the descending (b-c) and ascending (g-h) phases of the swing.

In a recent simulation study, Sprigings et al. (1998) developed a three-segment planar model to investigate the potential problem of removing unwanted swing in a handstand when performing a backward longswing. By varying the gymnast's technique and the initiation of the longswing with respect to the angle of the rings cables from the vertical, an initial handstand displaying $10^{\circ}$ of swing-amplitude was reduced to $1.5^{\circ}$ swing in the final handstand. Furthermore, the study found that when commencing the longswing from a stationary handstand the model could not produce a final handstand with less than $3^{\circ}$ residual swing.

This raises the question of whether the residual swing can theoretically be reduced to zero using a sufficiently detailed simulation model. If this is so and a gymnast should be able to produce zero residual swing using perfect technique and perfect timing then what are the practical limits of performance? This paper will address these two questions using a three-dimensional model of a gymnast and rings apparatus incorporating elastic structures.

\section{Methods}

The methods comprised: the collection of force and video data for a backward longswing, the development and evaluation of a three-dimensional simulation model of swinging on rings, the optimisation of longswing performance and the sensitivity of the optimised performance to changes in the timing of the gymnast's technique.

\section{Data collection}

A three-dimensional cable tension and video analysis was conducted on a backward longswing performed by an elite gymnast in the training environment. Anthropometric data were collected on the gymnast using the procedure of Yeadon (1990b) to determine personalised segmental inertia parameters. 
Prior to the performances a calibration structure comprising 12 markers in known locations, encompassing a volume measuring $1.8 \mathrm{~m} \times 1.8 \mathrm{~m} \times 5.7 \mathrm{~m}$, was centred between the uprights of the rings frame and was video-recorded from two camera views. Subsequently several straight arm backward longswings from "motionless" handstands were video-recorded using two genlocked Hi 8 video cameras operating at $50 \mathrm{~Hz}$ with electronic shutter speeds of $1 / 250 \mathrm{~S}$. A national coach assessed the proficiency of each swing. The best performance, possessing limited motion in the final handstand, was selected and used in the following analysis.

Cable tension was measured throughout the longswings by a quartz force link (Kistler, 9331A) placed in series within a specially constructed rings cable attached to a standard competition rings frame. A two-way manual trigger initiated force capture and simultaneously illuminated an array of light emitting diodes which was used to synchronise tension and video data to within half a video field.

\section{Data processing}

Personalised segmental inertia parameters for the subject were calculated using the mathematical inertia model of Yeadon (1990b). A truncated Fourier series was used to attenuate systematic and random noise at frequencies greater than $45 \mathrm{~Hz}$ in the raw cable tension data.

The images of the 12 calibration markers were digitised from each camera view. For the longswing sequence 15 body landmarks were digitised from each camera view: the left and right wrist, elbow, shoulder, hip, knee and ankle joint centres, the left and right toes and the centre of the head. A further four apparatus landmarks were also digitised from each view: the pivot attachments of the rings cables and the left and right hands grasping the rings. The direct linear transformation (DLT) procedure (Abdel-Aziz and Karara, 1971) was used to calibrate the camera-digitiser systems and to reconstruct the three-dimensional locations of the digitised landmarks on the gymnast and rings apparatus throughout the longswing.

The orientation angles of the gymnast and rings cables, the gymnast's body configuration angles, and the mass centre location of the gymnast were calculated using the method described by Yeadon (1990a). The rotation angle $\varepsilon$, calculated as the angle between the vertical and a line joining the gymnast's mass centre to the midpoint of the hands, described the overall orientation of the gymnast. The rotation angle was close to $0^{\circ}$ in the initial handstand and close to $360^{\circ}$ in the final handstand. The orientation of the rings cables in the inertial reference frame was defined by successive rotations through the cable elevation angle $\phi_{c}$ and the cable abduction angle $\theta_{c}$. Five body segments were defined from the digitised articulations of the gymnast: two arms, torso+head, thighs, and shanks+feet. From these segments the torso angle $\phi_{t}$ was calculated to define the orientation of the gymnast and four angles were calculated to describe the configuration of the gymnast: arm elevation $\phi_{a}$, arm abduction $\theta_{a}$, knee angle $\phi_{k}$ and hip angle $\phi_{h}$. The wrist to ankle length was calculated as the sum of the lengths of the shank, thigh, torso and arm segments. The configuration and orientation angles of the gymnast and rings cables and the extension of the gymnast were fitted using quintic splines to obtain continuous time histories and first and second derivatives (Wood and Jennings, 1979).

\section{The simulation model}

The software package AUTOLEV $\mathrm{TM}_{3}$ was used to develop the three-dimensional simulation model of a gymnast swinging on rings (Fig. 2). 

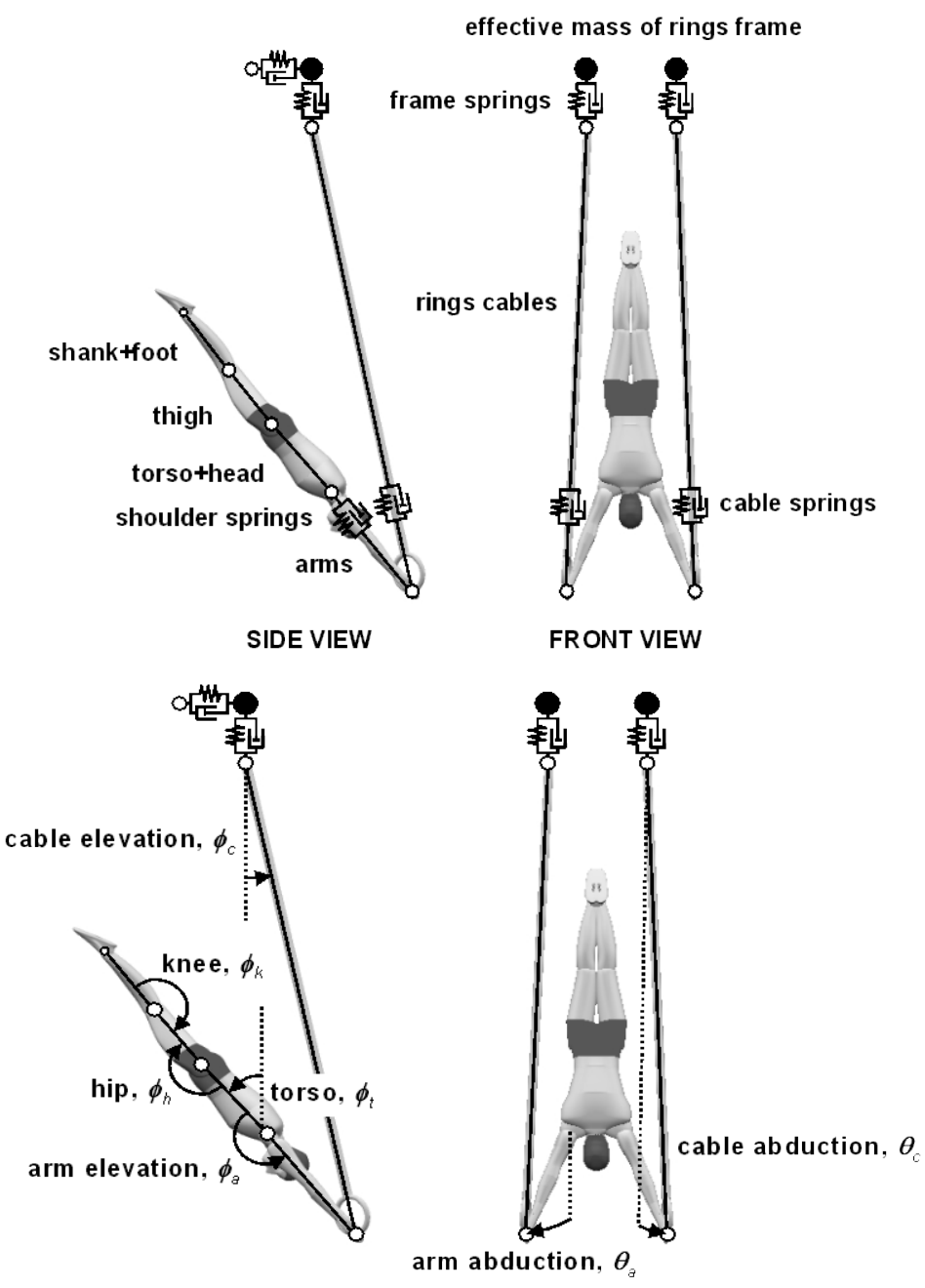

Fig. 2. The structure of the three-dimensional simulation model of a gymnast swinging on rings and the model's orientation and configuration angles.

Constraint equations were used to ensure symmetrical motion of the model relative to the sagittal plane. Large masses at the top of the cables represented the effective mass of the rings frame. The rings cables were represented by two rigid segments with orientations described by $\phi_{c}$ and $\theta_{c}$. Damped linear springs represented the elasticity of the frame in the horizontal direction, the damped elastic devices (DEDs) in the vertical direction and the elasticity of the rings cables along their length.

The modelled gymnast comprised five rigid segments: two arms, a torso+head, a thigh, and a shank+foot (Fig. 2). The orientation and configuration of the model was specified by the angles $\phi_{t}, \phi_{a}, \theta_{a}, \phi_{k} \phi_{h}$. Non-linear damped springs, with force as a quadratic function of extension, were introduced at the shoulders to represent the compliance of the gymnast, similar to modelling the visco-elastic properties of the heelpad in running (Gerritsen et al., 1995; Cole et al, 1996; Pain \& Challis, 2001).

Input to the model comprised the gymnast's technique throughout a simulation described in terms of the four body configuration angle time histories and their first two derivatives. Initial conditions consisted of the angle and angular velocities of the model's torso and rings cables and the lengths and velocities of all springs. Output from the model comprised the resulting motion of the rings cables and gymnast, the combined cable tension, the wrist to ankle length of the gymnast and the net joint torques. A 
three-dimensional computer graphics model of the human body (constructed using Open Inventor ${ }^{\mathrm{TM}}$, SGI) was used to illustrate orientation and configuration data with graphics sequences.

\section{Parameter determination and model evaluation}

The inertial properties of the frame and rings cables were based on measurements taken from the apparatus used in the data collection. The inertial properties of the gymnast model were personalised to the elite gymnast using the inertia model of Yeadon (1990b).

A simulated annealing optimisation algorithm (Goffe et al., 1994) was employed to determine values for the spring parameters (stiffness and damping for the horizontal beam of the frame, the DEDs, the rings cables and the gymnast's shoulders) representing the elasticity of the apparatus and gymnast. The initial conditions and the spline fitted joint angle time histories, taken from the recorded performance, were used as input to the simulation model. Weighted root mean squared (rms) differences between the measured and simulated rotation angle $\varepsilon$, cable elevation angle $\phi_{c}$, cable tension $T$ and wrist to ankle length wa throughout the longswing were summed to give an evaluation score $S_{e}$ (equation 1 ) which was minimised by the optimisation routine. Weightings $\left(W_{1}-W_{4}\right)$ were based on the ranges of the data from the actual performance to provide equivalence between the four components of the evaluation score. For example, the total excursions of the rotation angle $\varepsilon$ and cable elevation angle $\phi_{c}$ during the longswing were approximately $360^{\circ}$ and $60^{\circ}$ respectively. The weightings used in $\mathrm{S}_{\mathrm{e}}$ were inversely proportional to these excursion values.

$$
\begin{aligned}
\text { eval }= & W_{1} \sqrt{\frac{\sum\left(\varepsilon_{m}-\varepsilon_{s}\right)^{2}}{n}}+W_{2} \sqrt{\frac{\sum\left(\phi_{c_{m}}-\phi_{c_{s}}\right)^{2}}{n}}+W_{3} \sqrt{\frac{\sum\left(T_{m}-T_{s}\right)^{2}}{n}}+W_{4} \sqrt{\frac{\sum\left(w a_{m}-w a_{s}\right)^{2}}{n}} \ldots \\
& \text { where; } W_{1}=1 / 6, \quad W_{2}=1, \quad W_{3}=1 / 220 \text { and } W_{4}=33^{1 / 3}
\end{aligned}
$$

\section{Optimisation of the backward longswing performance}

Judging criteria defined by the F.I.G. (1997) for longswings on rings were used to develop a performance score $S_{p}$ (equation 2). For the "perfect" longswing a gymnast must attain a motionless final handstand which requires the cable elevation angle $\phi_{c}$, cable angular velocity $\dot{\phi}_{c}$ and the rotation angular velocity $\dot{\varepsilon}$ to be zero, and the rotation angle $\varepsilon$ to be $360^{\circ}$. The score at each time step of a performance or simulation was defined as the sum of squares of these four variables (equation 2). A simplified representation of the gymnast and rings cables as a point mass double pendulum with $3 \mathrm{~m}$ cables and $1 \mathrm{~m}$ gymnast was used to determine the weightings $\left(W_{5}-W_{8}\right)$ using potential and kinetic energy to establish equivalence of angles and angular velocities. The minimum value of the score during the ascending phase of the actual performance or simulation was taken as the performance score and reflected the amount of residual swing, in terms of the cable elevation angle, in the final handstand (equation 3).

$$
\begin{aligned}
& \text { perf }=\min \left(W_{5}\left(2 \pi-\varepsilon_{s}\right)^{2}+W_{6}\left(\dot{\varepsilon}_{s}\right)^{2}+W_{7}\left(\phi_{c_{s}}\right)^{2}+W_{8}\left(\dot{\phi}_{c_{s}}\right)^{2}\right) \\
& \text { where; } W_{5}=5, \quad W_{6}=1, \quad W_{7}=15 \text { and } W_{8}=3 \\
& \text { residual swing }=\sqrt{\frac{p e r f}{15}}
\end{aligned}
$$

The performance score was calculated for the actual longswing in order to provide a baseline measurement of the gymnast's performance and for comparison with the simulated longswing as a further check on the accuracy of the model. In order to 
optimise the performance using the simulation model the gymnast's recorded technique was modified. To achieve this each joint angle time history of the gymnast's actual technique was re-sampled at $10 \mathrm{~Hz}$ to provide reduced data sets representing the joint angle time histories. The reduced data sets of the hip, arm elevation and arm abduction angles (29 parameters per joint angle, 87 parameters in total) were modified by the simulated annealing algorithm to minimise the performance score.

Realistic upper and lower bounds for the magnitudes of angle changes were used to ensure that the technique remained realistic. The hip and arm elevation angles were allowed to deviate from those in the real performance by up to $10^{\circ}$. Arm abduction angles were allowed to vary by as much as $50^{\circ}$ from those observed in the actual performance, allowing the optimisation process to omit or include lateral arm movements in the search for the optimum performance. Joint torques were constrained to lie within maximum values obtained from the evaluation simulation to ensure angle changes were within the strength limits of the gymnast. In order to adhere further to judging requirements the joint angles on completion of the longswing were constrained to represent a realistic handstand configuration.

\section{Sensitivity of the optimised performance}

Simulations were conducted to assess the sensitivity of the optimised performance to perturbations in technique. In each simulation a delay (from $5 \mathrm{~ms}$ to $40 \mathrm{~ms}$ ) in the timing of one or more aspects of the technique in the optimised performance was initiated during the ascending phase of the swing (rotation angle $\varepsilon>208^{\circ}$ ). This phase of the swing was chosen as the focus for technique manipulation since it ensured changes were within the strength limitations of the gymnast.

\section{Results}

\section{Inertia parameters}

Values for the inertial parameters of the rings apparatus and personalised segmental values for the gymnast in the video and simulation model are presented in Table 1.

Table 1. Inertia parameters of the rings cables and body segments in the simulation model

\begin{tabular}{|c|c|c|c|c|c|c|}
\hline & $\begin{array}{l}\mathrm{l} \\
\mathrm{e}\end{array}$ & $\begin{array}{l}\mathrm{m} \\
\mathrm{a}\end{array}$ & $\begin{array}{l}\text { mass } \\
\text { centr }\end{array}$ & \multicolumn{3}{|c|}{$\begin{array}{l}\text { principal moment of inertia } \\
\qquad\left(\mathrm{kg} \cdot \mathrm{m}^{2}\right)\end{array}$} \\
\hline segment & & & & $\mathrm{fr}$ & trans & longi \\
\hline each rings & & 1 & & & & \\
\hline each rings & 2 & 1 & 1.46 & 0. & 0.71 & 0.00 \\
\hline each arm & 0 & 3 & 0.35 & 0. & 0.12 & 0.00 \\
\hline torso+hea & 0 & 3 & 0.12 & & 1.62 & \\
\hline thigh & 0 & 1 & 0.17 & & 0.23 & \\
\hline shank+foo & 0 & 8 & 0.23 & & 0.24 & \\
\hline
\end{tabular}




\section{Model evaluation}

The stiffness and damping parameters for the model's springs determined in the evaluation procedure are provided in Table 2.

Table 2. Spring stiffness and damping coefficients determined from the evaluation procedure

\begin{tabular}{ccccc} 
& \multicolumn{4}{c}{ model springs } \\
\cline { 2 - 5 } & horiz & vertic & ca & shoulder \\
\hline stiffness & 2013 & 6874 & 24 & 24855, \\
damping & 91 & 4424 & 26 & 1901 \\
\hline
\end{tabular}

Note: * The shoulder spring is non-linear producing a force of $\mathrm{Ax}^{2}+\mathrm{Bx}+\mathrm{C} \dot{\mathrm{x}}$ for an extension $\mathrm{x}$. The table lists the values of the stiffness constants A and B and damping constant C.

A comparison of simulation and video data shows that the model gives an accurate representation of a backward longswing (Fig. 3).
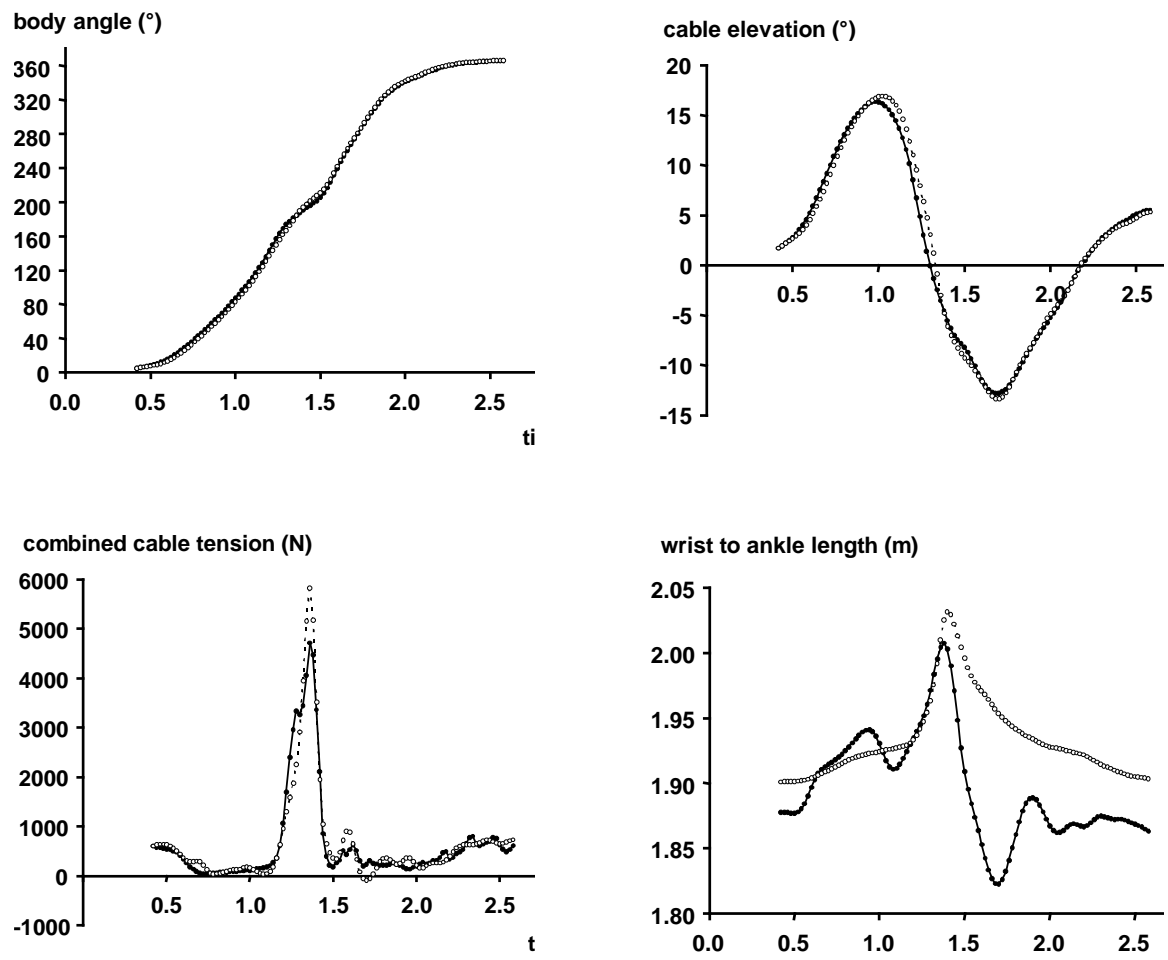

Fig. 3. Evaluation of the simulation model: a graphics sequence comparing the orientations of the gymnast and rings cables during the actual performance (upper) and the corresponding simulation (lower) of the backward longswing; time histories of the gymnast and cable orientation, combined cable tension and wrist to ankle length for the actual performance (closed circles) and the simulation (open circles). 
The rms differences between the actual and simulated values for the components of the evaluation score were $3.2^{\circ}$ for the rotation angle, $1.0^{\circ}$ for the cable elevation angle, $270 \mathrm{~N}$ for the combined cable tension and $0.05 \mathrm{~m}$ for the wrist to ankle length. When expressed as a percentage of their total measured excursions these differences are equivalent to $0.9 \%$ for rotation angle, $1.5 \%$ for cable elevation angle, $5.7 \%$ for combined cable tension and $12.7 \%$ for wrist to ankle length.

The optimised backward longswing performance

Using the performance score $S_{p}$ with the data derived from the video analysis: the backward longswing performed by the elite gymnast started from a handstand with $2.1^{\circ}$ of swing and ended in a handstand with $8.0^{\circ}$ of residual swing. The residual swing for the simulated performance was $7.2^{\circ}$. The optimised performance was very similar to the evaluation simulation (Fig. 4) and had a performance score equivalent to $0.6^{\circ}$ of residual swing.

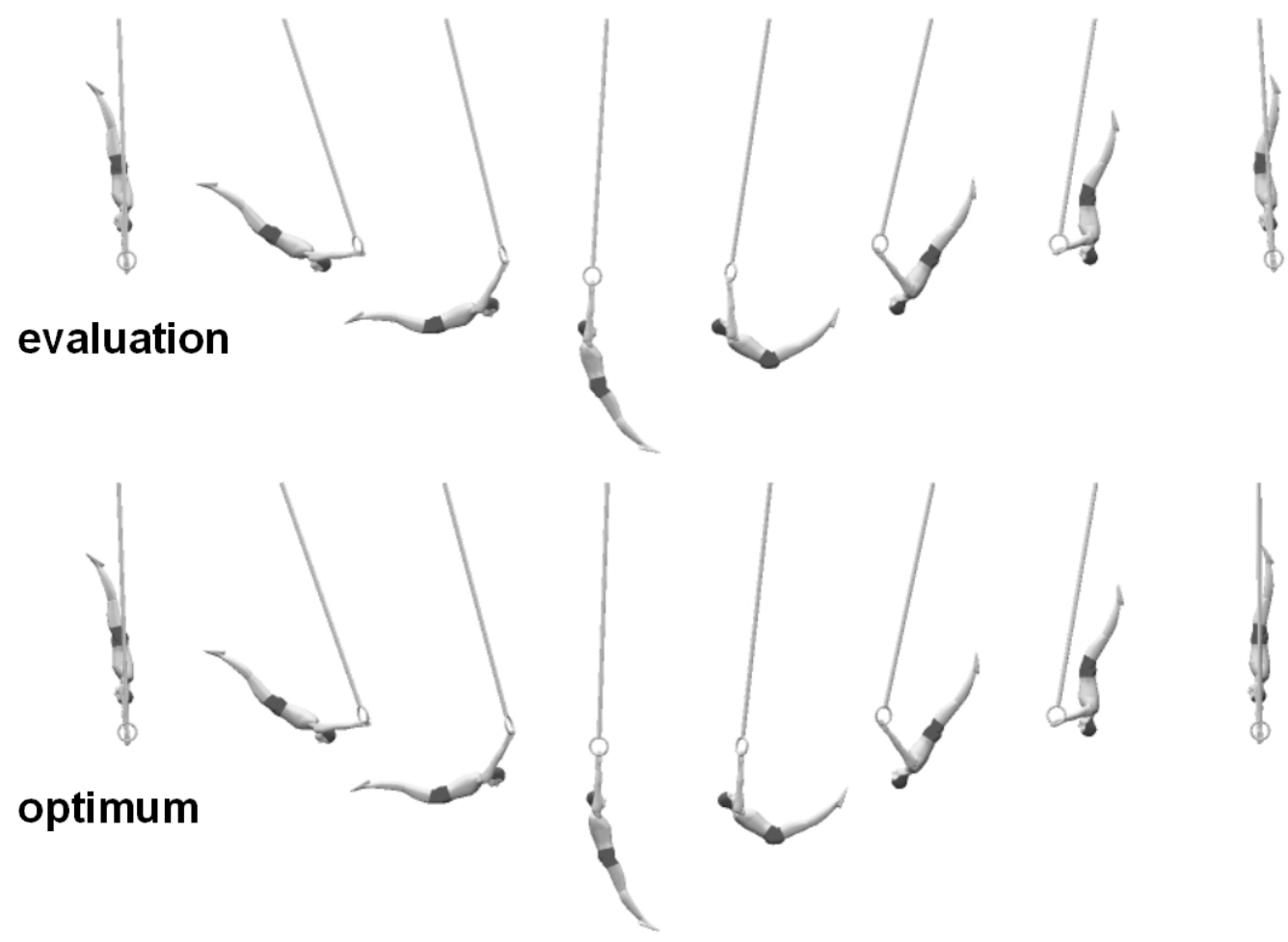

Fig. 4. Graphics sequence showing the orientations of the gymnast and rings cables for the simulation model during the evaluation simulation (upper) and the optimised simulation (lower) of the backward longswing.

Fig. 5 illustrates the difference in technique between the evaluation and the optimised simulations. A clear difference occurred in the hip angle from $2.0 \mathrm{~s}$ onwards, when the rotation angle was $345^{\circ}$, while minor differences can be observed in the arm elevation angle from $2.2 \mathrm{~s}$ onwards. Peak joint torque values for the evaluation simulation ranged between $300 \mathrm{~N} \cdot \mathrm{m}$ and $-170 \mathrm{~N} \cdot \mathrm{m}$ at the combined hip joint and between $164 \mathrm{~N} \cdot \mathrm{m}$ and $-146 \mathrm{~N} \cdot \mathrm{m}$ at each shoulder joint (where positive values correspond to a tendency to reduce the joint angle). The corresponding peak torques for the optimised longswing were $240 \mathrm{~N} \cdot \mathrm{m}$ and $-170 \mathrm{~N} \cdot \mathrm{m}$ (hip) and $141 \mathrm{~N} \cdot \mathrm{m}$ and $-109 \mathrm{~N} \cdot \mathrm{m}$ (shoulder). These peak torques in the optimised performance were lower than those in the evaluation simulation and occurred at lower angular velocities, indicating that the optimised performance did not exceed the strength limits of the elite gymnast. 

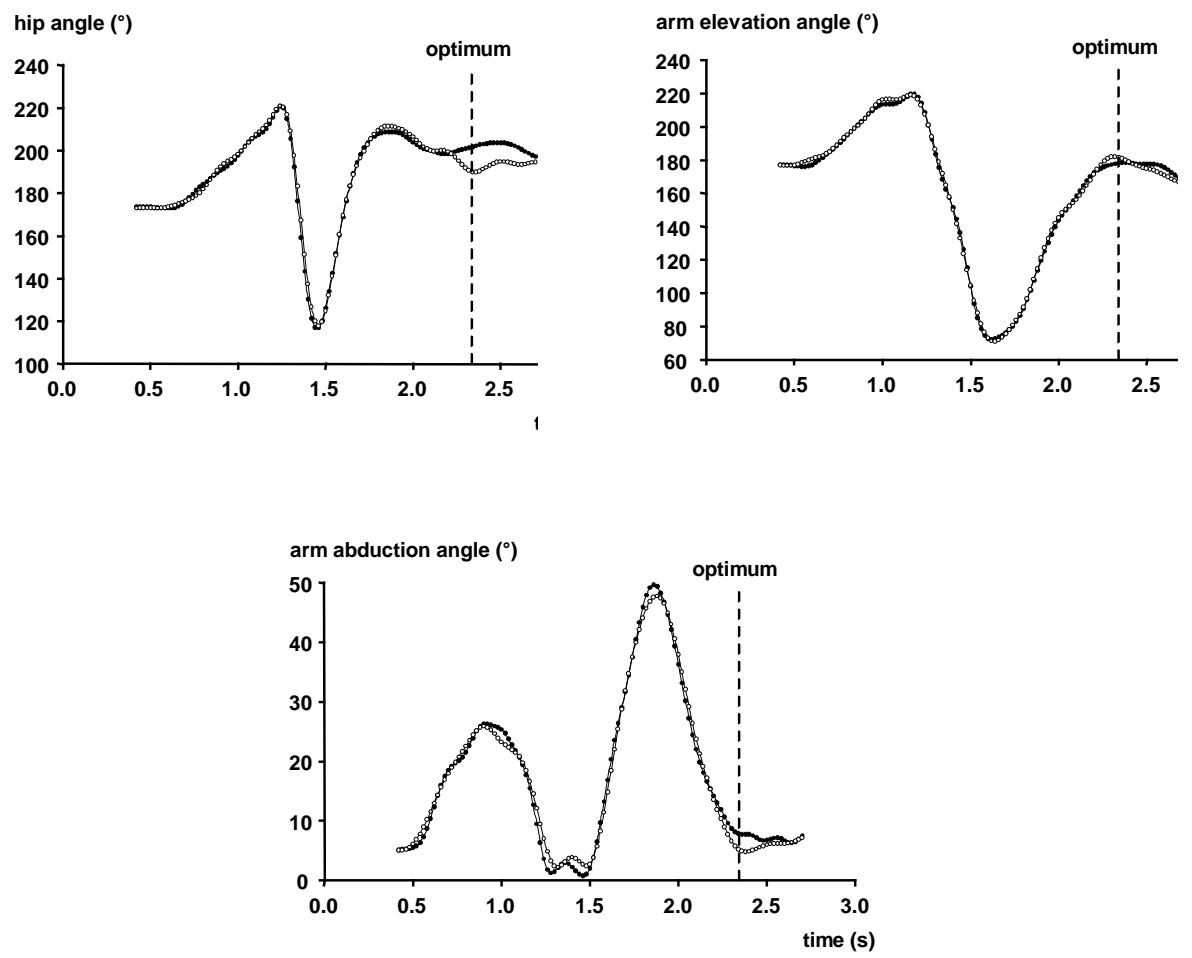

Fig. 5. Joint angle time histories used in the evaluation (closed circles) and the optimised simulations (open circles). The vertical broken line indicates the instant in time at which the optimised simulation had minimum swing according to the performance score $S_{p}$.

\section{Sensitivity of the optimised backward longswing}

With 20 ms delays introduced in each of the three components of technique (hip angle, arm elevation and arm abduction) during the ascending phase of the swing, the resulting performance can be seen to degrade from the optimum (Fig. 6). 

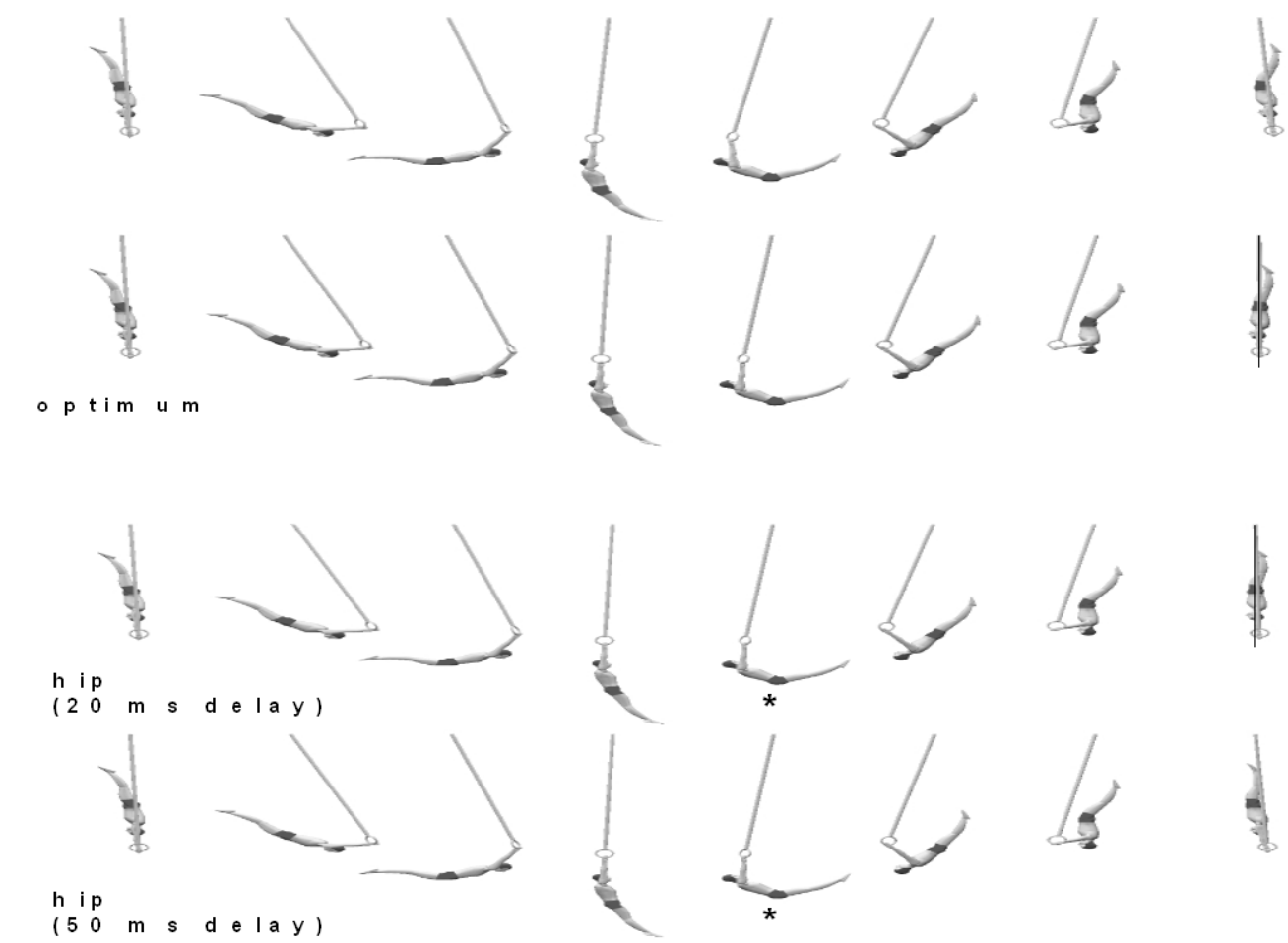

( $50 \mathrm{~m}$ s d e lay)
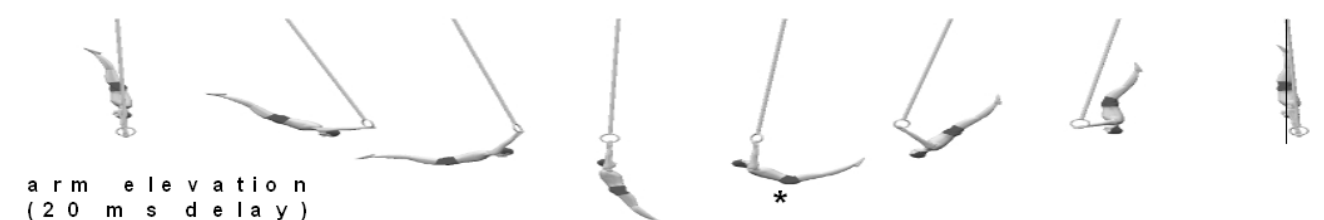

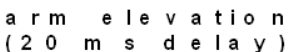
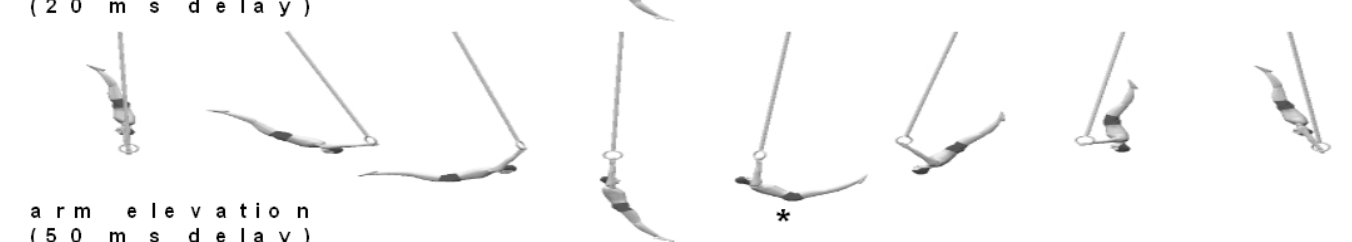

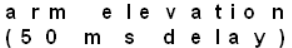
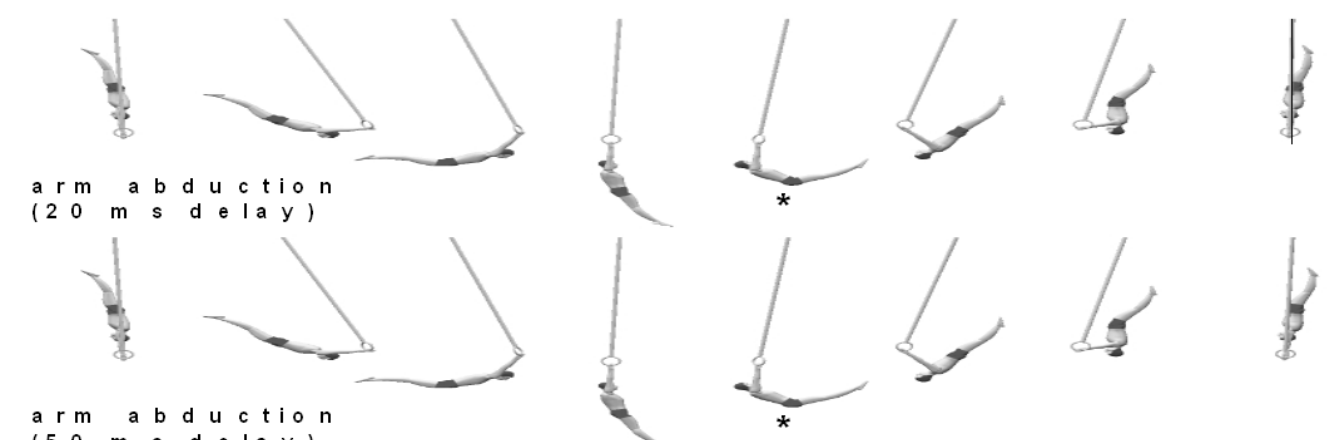

Fig. 6. Graphics sequences highlighting the effects of delaying selected aspects of the gymnast's technique: hip angle, arm elevation angle and arm abduction angle used during the optimised simulation. The asterisks indicate the point of the swing at which the delay of $20 \mathrm{~ms}$ was initially introduced in each aspect of technique.

Objective measures of these changes in performance are given by the performance scores for delays ranging from $5 \mathrm{~ms}$ to $40 \mathrm{~ms}$ in each joint angle (Table 3). In general the delay introduced into the arm elevation time history produced the largest changes in performance while the delay in the hip angle resulted in the smallest changes in residual swing. 
Table 3. Residual swing scores when technique was delayed from the optimum

\begin{tabular}{ccccc} 
& \multicolumn{3}{c}{ score $\left(^{\circ}\right)$} & \\
\cline { 2 - 5 } delay & hip & $\begin{array}{c}\text { arm } \\
\text { elevation }\end{array}$ & arm \\
abduction & all \\
\hline 0.000 & 0.6 & 0.6 & 0.6 & 0.6 \\
0.005 & 0.8 & 1.3 & 1.4 & 1.0 \\
0.007 & 0.9 & 1.9 & 1.9 & 1.1 \\
0.008 & 0.9 & 3.1 & 2.1 & 1.2 \\
0.010 & 1.0 & 3.8 & 2.4 & 2.4 \\
0.015 & 1.1 & 5.3 & 3.0 & 3.9 \\
0.020 & 1.3 & 7.3 & 3.8 & 7.6 \\
0.030 & 2.5 & 10.8 & 5.4 & 8.9
\end{tabular}

Note: "all” denotes that all three angles were delayed (by the same amount)

\section{Discussion}

Unlike the study of Sprigings et al. (1998) where only a subjective validation of the model was presented, in the present study an objective evaluation against an actual backward longswing performance was conducted. In general, the evaluation indicates that the three-dimensional model provided an accurate representation of a gymnast performing a backward longswing on rings. The angular motion of the gymnast and rings cables were particularly close to the actual performance and this provides additional support for their use in the performance score. The accuracy of the model may be attributed to the inclusion of lateral arm movements used by elite gymnasts, the representation of the mandatory elastic properties of the apparatus outlined by the F.I.G. (1989), and the non-linear damped spring used to represent shoulder compliance. While these factors have all been shown to be important in altering peak loading at the shoulders during longswings, increasing apparatus elasticity produces only a small reduction in peak force at the shoulders (Brewin et al., 2000).

The evaluation procedure did, however, indicate the model was less accurate in simulating the gymnast's extension. Although the maximum extension experienced by the real gymnast during the longswing was similar in magnitude to the simulated extension (approximately $0.12 \mathrm{~m}$ ), the time histories differed considerably in the last half of the movement (Fig. 3). Much of this difference may be attributed to the lack of a representation of scapular rotation in the model resulting in an overestimation of the wrist-ankle length when the arms are lowered relative to the torso as in the sixth graphic of Fig. 3. Using a function based on the angle between the torso and arm segments and a maximum movement of the shoulder girdle of $0.095 \mathrm{~m}$, the rms difference between the actual and simulated wrist to ankle length was reduced from $0.053 \mathrm{~m}$ to $0.027 \mathrm{~m}$ (Fig. $7)$. 


\section{wrist to ankle length $(\mathrm{m})$}

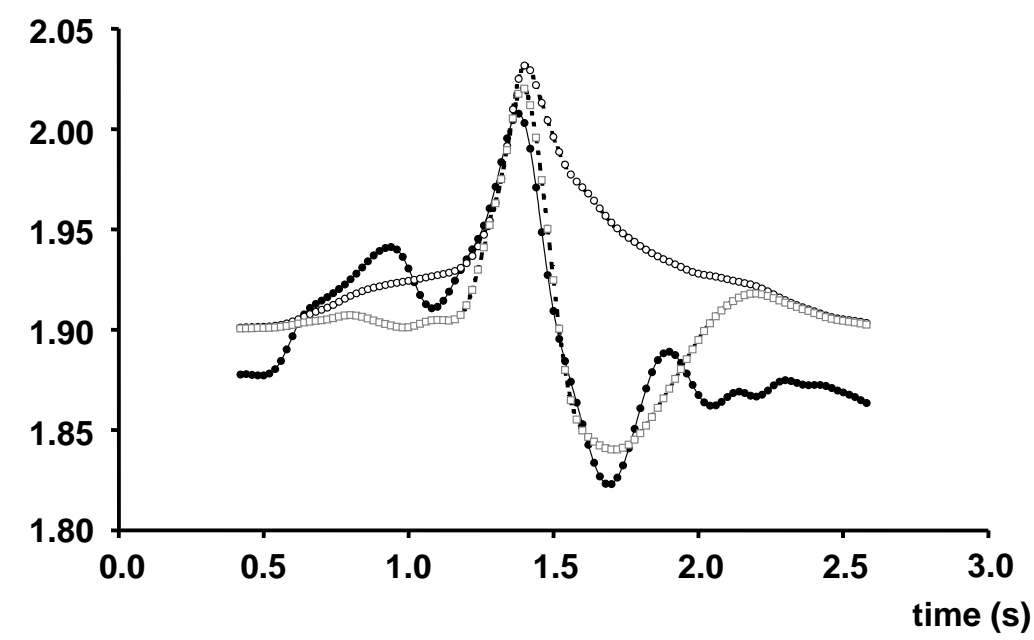

Fig. 7. The effect of including scapula rotation on the simulated wrist to ankle length. Time histories of the actual (closed circles) and simulated (open circles) wrist to ankle lengths and when scapula movement is considered (open squares). The adjusted wrist to ankle length $w a_{a}$ which considered scapula rotation was calculated as a function of the simulated length $w a_{s}$ and arm elevation $\phi_{a}$ and abduction $\theta_{a}$ angles:

$$
w a_{a}=w a_{s}-0.095\left(1+\cos \phi_{a} \cos \theta_{a}\right) .
$$

However, even after this adjustment, the wrist to ankle length of the model is still $0.03 \mathrm{~m}$ longer than the measured length when in the handstand position. This could be allowed for in the model by using a lower value for the shoulder spring stiffness when under compression.

In the actual performance of the longswing the initial handstand had $2.1^{\circ}$ of swing and the final handstand had $8.0^{\circ}$ of residual swing. In the optimised simulated longswing the residual swing was reduced to $0.6^{\circ}$ which may be considered to represent a still handstand in view of the limits of performance discussed below.

It should be noted that although the optimisation procedure allowed the magnitude of lateral arm movements to vary from zero to $50^{\circ}$ more than those typically used, the optimised longswing utilised movements similar to those of elite gymnasts. The lateral arm movements may provide the gymnast with more opportunities to make the task of performing the backward longswing easier and therefore contribute to a successful performance.

To establish how much residual swing elite gymnasts exhibit after a longswing to handstand four performances from the 1992 Olympics were identified for which the residual swing was minimal and a further four for which the residual swing was large. The mean residual swings for these two groups were $2.3^{\circ} \pm 0.6^{\circ}$ and $7.6^{\circ} \pm 1.5^{\circ}$. The sensitivity analysis indicates that a delay of $7 \mathrm{~ms}$ in one aspect of arm movement or a delay of $15 \mathrm{~ms}$ in all three aspects of technique will result in a residual swing of $2^{\circ}$ while a delay of $20 \mathrm{~ms}$ in arm elevation or a $30 \mathrm{~ms}$ delay in all three angles will result in a residual swing of $7^{\circ}$ (Table 3 ).

It may be concluded that elite gymnasts can time their movements to better than $30 \mathrm{~ms}$. If the best gymnasts can consistently produce no more than $2^{\circ}$ of residual swing there are two possible explanations. Either these gymnasts can time their movements to within $15 \mathrm{~ms}$ or they use techniques that are less sensitive to timing errors than the optimised solution found in this study. 


\section{References}

Abdel-Aziz, Y.I., Karara, H.M., 1971. Direct linear transformation from comparator coordinates into object space coordinates in close range photogrammetry. (ASP Symposium on Close-Range Photogrammetry). Falls Church, VA: American Society of Photogrammetry, pp 3-18.

Brewin, M.A., Yeadon, M.R., Kerwin, D.G., 2000. Minimising peak forces at the shoulders during backward longswings on rings. Human Movement Science, 19, 717-736.

Brüggemann, G.-P., 1987. Biomechanics in gymnastics. In: Hebbelinck, M., Shephard, R.J (Eds.), Medicine and Sports Science. Basel: Karger, pp 142-176.

Cole, G.K., Nigg, B.M., van den Bogert, A.J., Gerritsen, K.G.M. 1996. Lower extremity joint loading during impact running. Clinical Biomechanics, 11, 181193.

Fédération Internationale de Gymnastique (F.I.G.), 1997. Code of Points. Artistic Gymnastics for Men (1997 edition). Switzerland: F.I.G.

Fédération Internationale de Gymnastique (F.I.G.), 1989. Apparatus norms for official events of artistic gymnastics and rhythmic sportive gymnasts. Switzerland: F.I.G., pp 56-62.

Gerritsen, K.G.M., van den Bogert, A.J., Nigg, B.M. 1995. Direct dynamics simulation of the impact phase in heel-toe running. Journal of Biomechanics, 28, 661-668.

Goffe, W.L., Ferrier, G.D., Rogers, J., 1994. Global optimisation of statistical functions with simulated annealing. Journal of Econometrics, 60, 65-99.

Nissinen, M.A., 1983. Kinematic and kinetic analysis of the giant swing on rings. In: Matsui, H., Kobayashi, K,. (Eds.), Biomechanics VIII-B. Champaign, IL: Human Kinetics, pp 781-786.

Pain, M.T.G., Challis, J.H. 2001. The role of the heel pad and shank soft tissue during impacts: a further resolution of a paradox. Journal of Biomechanics, 34, 327-333.

Sprigings, E.J., Lanovaz, J.L. Russell, K.W., 2000. The role of shoulder and hip torques generated during a backward giant swing on rings. Journal of Applied Biomechanics, 16, 289-300.

Sprigings, E.J., Lanovaz, J.L., Watson, L.G., Russell, K.W., 1998. Removing swing from a handstand on rings using a properly timed backward giant circle: a simulation solution. Journal of Biomechanics 31, 27-35.

Wood, G.A., Jennings, L.S., 1979. On the use of spline functions for data smoothing. Journal of Biomechanics 12, 477-479.

Yeadon, M.R., 1990a. The simulation of aerial movement - I. The determination of orientation angles from film data. Journal of Biomechanics 23, 59-66.

Yeadon, M.R., 1990b. The simulation of aerial movement - II. A mathematical inertia model of the human body. Journal of Biomechanics 23, 67-74. 